\title{
EL LENGUAJE COMO SÍMBOLO SEMÁNTICO Y EMOTIVO
}

Carmen Loza Ardila Universidad de Sevilla

En sentido general existen muchos lenguajes, puesto que se entienden éstos como una forma de comunicación; de ahí que la comunicación mímica, de señales, etc. sean sistemas de lenguaje. Nos referimos, en este caso, a la comunicación por medio de palabras.

El lenguaje sería, pues, un sistema de comunicación que emplea un conjunto de signos y símbolos * (palabras escritas o verbales), para representar nuestro pensamiento, sentimientos y emociones. El lenguaje es, por ello, un mecanismo que hace posible la materialización de los contenidos psíquicos.

Para que exista comunicación es necesario que haya relación entre lo que se desea expresar y el símbolo (palabra) elegido, siendo esto un requisito que nos diferenciaría, por ejemplo, de ciertos animales capaces de emitir palabras. Las palabras deben estar, además, integradas dentro de un sistema. Levi-Strauss ${ }^{1}$, que equiparaba los fenómenos lingüísticos con los de parentesco, sostenía que éstos, como los sistemas fonológicos, son elaborados por el entendimiento en estado de pensamiento inconsciente.

Van Sommer ${ }^{2}$, basándose en otros autores, confirma que en las funciones del lenguaje interviene un tejido nervioso especializado, que está situado en las regiones parietal, temporal y frontal de la corteza, generalmente en el lado izquierdo del cerebro.

* De forma general, vamos a considerar en este trabajo los términos signo y símbolo como sinónimos, aunque se pueden hacer matizaciones semánticas.

1 LEVI-STRAUSS, C. (1968) «Antropología estructural». EUDEBA. Ed. Universitaria. Buenos Aires.

2 VAN SOMMERS, P. (1976) «Biología de la conducta». Ed. Limusa. Méjico. 
Para Piaget ${ }^{3}$ la inteligencia es anterior e independiente del pensamiento y del lenguaje, $\mathrm{y}$ «ambos dependen, a fin de cuentas, de la propia inteligencia» (p. 124), por lo que la inteligencia se modifica profundamente gracias al lenguaje. Eberhart ${ }^{4}$ y Oléron ${ }^{5}$, por ejemplo, estaban de acuerdo con esta postura, pero en este punto hay gran controversia, existiendo partidarios de que el lenguaje es la fuente del pensamiento y quienes sostienen lo contrario. Tanto en un caso como en otro, e independientemente de que sea el lenguaje quien genere el pensamiento, o el pensamiento el lenguaje, lo que sí es patente es que ambos están en estrecha comunicación, tanto que durante mucho tiempo se midió la capacidad mental por el tipo de lenguaje.

¿Cuándo aparecen las primeras palabras? Ante todo hay que diferenciar entre sonido y palabra, ya que, para que el sonido sea palabra, es necesario que eśte sea un símbolo, es decir, la representación de algo y, por tanto, que tenga un significado. Generalmente las primeras palabras son monosílabos cargados de emotividad, siendo, al principio, sólo sonidos que el niño imita, pero sin significado simbólico, hasta que, por la reiteración de ellos y ante situaciones diversas, consigue relacionar el sonido concreto con una situación específica correspondiente a dicho fonema. Es cuando las palabras se hacen representativas de esas situaciones.

El lenguaje es, por tanto, un conjunto de símbolos, ya que sus distintos elementos son representativos de otros elementos, situaciones, etc. Pero, al mismo tiempo, existen otras clases de símbolos, otras situaciones o artilugios que representan otras escenas u objetos. Es lo que Piaget ${ }^{6}$ llama «otros sistemas de significantes» (p. 112). Tanto los símbolos como el lenguaje son propios de cada cultura.

Los símbolos son estudiados en profundidad por el psicoanálisis. Freud ${ }^{7}$ interpreta a la simbólica como el conjunto de símbolos dotados de significación y que pueden encontrarse en diversas producciones del inconsciente, y señala que «la comunidad de símbolos traspasa en muchos casos la comunidad del idioma» (p. 559). Es decir, que para un único objeto (por tanto, debe nombrarse por una sola palabra) puede haber multitud de símbolos: «cuando el sujeto elegir entre varios símbolos para representar cierto contenido, se decidirá por aquél que entrañe, además, relaciones objetivas con su restante material ideológico» (p. 560).

Por otra parte, y retomando a Piaget ${ }^{8}$, se fija este autor en varias clases de representaciones simbólicas, como el juego simbólico, la imitación diferida, los símbolos individuales y los oníricos. El niño empieza a utilizar los símbolos al mismo tiempo que el lenguaje, aunque independientemente de él, pero el simbo-

3 PIAGET, J. (1973) «Seis estudios de psicología». Barral Editores. Barcelona.

4 EBERHART (1940) «A summary of some preliminary investigations of the deaf». Citado por CALOGNI, ob. cit.

5 OLERON (1957) «Recherche sur le development mental des souds muets». Citado por CALOGNI, ob. cit.

6 PIAGET, J. (1973) «Seis estudios de psicología». Barral Editore. Barcelona.

7 FREUD, S. (1900) «La interpretación de los sueños». Obras completas. Biblioteca Nueva. Tomo II. Madrid, 1972.

8 PIAGET, J. (1973), «Seis estudios de psicología». Barral Editores. Barcelona. 
lismo sirve precisamente para la adquisición de éste. Por tanto, convienen Piaget y Freud en que existe una función simbólica más amplia que el lenguaje, y que la fuente del pensamiento debe encontrarse en la función simbólica, ya que el lenguaje es una forma de esa función, concluyendo que el pensamiento precede al lenguaje, limitándose éste a transformar profundamente y aquél y «ayudándole a alcanzar su forma de equilibrio» (Piaget, p. 115).

Se deduce, por lo anterior, que los símbolos, incluyendo al lenguaje, son una forma de expresión y también de regulación del aparato psíquico.

Por ello, nos parece adecuado señalar que en la aparición del lenguaje interviene, además del juego sensomotor y de la imitación, un tercer elemento que es el afectivo. «Las necesidades afectivas regulan el desarrollo del lenguaje» (Calogni, p. 557) ${ }^{9}$. Los niños parecen utilizar el lenguaje para satisfacer sus necesidades, no sólo alimentarias (dando los primeros gritos) sino también afectivas. El lenguaje es un medio de contacto con su madre, que implica el contacto y el intercambio afectivo. La primera palabra suele ser una intejección y los sustantivos suelen ser pronunciados con una inflexión de exclamación o interjección. El lenguaje comienza a desarrollarse sobre un fondo emotivo de las relaciones entre el niño y su madre, lo que explica que los niños criados en instituciones presenten un retraso en su desarrollo lingüístico, y también ciertas regresiones del lenguaje en niños con situaciones conflictivas.

Sobre ese marasmo de sonidos y su ulterior con versión en palabras con significado se va construyendo la realidad. El lenguaje ayuda a la construcción de la realidad, tanto que para Lacan ${ }^{10}$ toda realidad human no adquiere su sentido hasta que no es expresada, aunque previamente haya sido pensada y representada. Sin embargo, Michael Foucault ${ }^{11}$, en «Las palabras y las cosas», se rebela contra la racionalidad del hombre, culpándola de la dominación que ejerce sobre éste, y atribuyendo al lenguaje el origen y fomento de esa racionalidad.

Existen multitud de ejemplos que demuestran la relación existente entre los conflictos emocionales y las alteraciones del lenguaj. Casanova ${ }^{12}$ y Ainsworth ${ }^{13}$, fijándose en las secuelas de la separación materna en niños pequeños, opinan que las reminiscencias de ellos se centran en el terreno de la personalidad, así como en el área del lenguaje.

Cuando al producirse una situación conflictiva, proveniente de la incapacidad de los padres para ponerse de acuerdo o para tomar decisiones conjuntas, el niño desarrolla unas características especiales, señalando entre éstas Block y

9 CALOGNI, L. et al. (1966) «Educar. Metodología de la investigación psicopedagógica». Ed. Sígueme. Salamanca.

10 LACAN, J. (1966) «Mas allá del principio de la realidad». Ecrits. Seuil. París, pp. 90-91.

11 FOUCAULT, M. (1977) «Las palabras y las cosas». En «El psicoanálisis». Enciclopedia del mundo actual Ed. Noguer. Barcelona.

12 CASANOVA, M. A. (1972) «La Falta de afecto en el niño». Consigna, n. 370-371, julioagosto. Madrid. p. 3-9.

13 AINSWORTH, M. D. (1961) «Les répercussions de la carence maternelle - faits observés et controverses dans le contexte de la stratégie des recherches». En «La carence des soins maternels»; reévaluation de ses effects». Cahiers de l'O.M.S., n. 14. Ginebra. 
colaboradores ${ }^{14}$ las dificultades de expresión verbal. También demostraron que los niños criados en hogares donde reinaba el acuerdo parental se caracterizaban por la facilidad inventiva y exposición verbal.

Cunninghan y otros ${ }^{15}$ comprobaron los efectos que ejercían las madres que establecían un código de comunicació desviado respecto a sus hijos. Es decir, se basaron en dos grupos de niño con similares niveles de edad mental, pero cuyas madres se podían agrupar en aquellas cuya sintaxis y pronunciación eran correctas y aquellas otras que siempre ajustaban tanto la formación de frases como la pronunciación de las palabras a lo que ellas creían que los niños podían percibir o comprender mejor. El resultado fue que los hijos de estas madres presentaban retraso, no sólo del lenguaje, sino de las demás áreas escolares, así como aspectos especiales de su personalidad: menor frecuencia de interacción con sus madres, menor sensibilidad hacia éstas y, al mismo tiempo, una tendencia a juegos solitarios.

Iglesias Noguerol ${ }^{16}$ estudia los efectos de los malos tratos en los niños, encontrando que éstos presentan retraso en el desarrollo motor, cognoscitivo y del lenguaje.

Respecto a la esquizofrenia, Seva Díaz ${ }^{17}$ apunta que, debido a la desintegración del yo que se experimenta en esos sujetos, se evidencia en ellos distorsiones profundas en el terreno afectivo, de la conducta y del lenguaje.

Otra constatación de la relación entre la parcela afectiva y el lenguaje lo constituyen el hecho de que entre grupos de palabras con distinto significante respecto al contenido emocional o neutral de las mismas, se recuerdan y se expresan antes las palabras asociadas a emociones, según Lorenzo y Fernández ${ }^{18}$, aunque la percepción de palabras de contenido ansiógeno es más lenta en comparación con las palabras menos ansiógenas o neutrales. Esto implica un carácter defensivo.

Pero el lenguaje no solamente se desarrolla y está en íntima relación con los contenidos emocionales del individuo, tanto que se estimen perturbaciones en el lenguaje cuando el sujeto está en una situación traumática, sino que también sirve para regular, en ciertos casos, el equilibrio psíquico. El lenguaje es el medio de comunicación por el que se reduce el estado de tensión emotiva del sujeto. Es una forma de regular la energía desagradable sobrante, de descargarse del exceso del «quantum de afecto». Es decir, que cuando ocurre algún suceso de carácter desagradable, el afecto ligado a éste puede debilitarse por varias vías: venganza, lloro, etc. Pero, si se reprime, la reacción, queda el efecto ligado al recuerdo. Sin

14 BLOCK, J. H. et al. (1981) «Parental Agreement-Desagreement on Child- rearing Orientations and Gender-related Personality Correlates in Children». Child Development, 52, n. 3. pp. 965-974.

15 CUNNINGHAN, Ch. E. et al. (1981) «Behavioral and linguistic Developments in the Interactions of Normal and Retarded Children with their Mothers». Child Development, 52, n. 1, pp. 62-70

16 IGLESIAS NOGUEROL (1986) «Maduración psicológica y problemática familiar en niños asistidos en hogares infantiles ». Psiquis, enero-febrero, año III, vol. VII, p. 22-36.

17 SEVA DÍAZ (1986) «Psicopatología de la expresión en la esquizofrenia desde el punto de vista mitologemático, arquetípico y pictórico». Psicopatología, vol. 6, n. 4, pp. 312-321.

18 LORENZO, J. y FERNÁNDEZ (1986) «Efectos psicofisiológicos de estímulos verbales emocionales». Psiquis, sept. oct., año VIII, vol. VII, pp. 44-51. 
embargo, una forma de descarga emotiva, tanto de contenidos inconscientes como conscientes, consiste en la utilización de la palabra. En efecto, Freud ${ }^{19}$ afirma que «el hombre encuentra en la palabra un subrogado del hecho, con cuyo auxilio puede el afecto ser también casi iguamente descargado por reacción (abreagiert)» (p. 44). Se refiere, con ello, al mecanismo de la abreacción, por lo que se demuestra que el hombre encuentra en el lenguaje no sólo un medio de expresión, sino también de regulación psíquica, además de un sustantivo de la acción. El descubrimiento de la abreacción en la cura de ciertas enfermedades histéricas decidió el nacimiento del psicoanálisis, por lo que puede decirse que ambos sistemas (lenguaje y psicoanálisis) son aliados y al servicio del individuo. 
